Este é um artigo publicado em acesso aberto sob uma licença Creative Commons https://creativecommons.org/licenses/by-nc/4.0/

\title{
Contribuições e limitações do estágio pedagógico voluntário (EPV) para a formação de professores do curso de administração
}

\author{
Márcia Sierdovski ${ }^{1}$ \\ Sílvio Roberto Stefano ${ }^{2}$ \\ Marcia Aparecida Zampier ${ }^{3}$ \\ Elaine Aparecida Regiani de Campos ${ }^{4}$
}

Resumo: Este estudo apresenta uma reflexão sobre a formação de professores da Graduação em Administração da Universidade Estadual do Centro-Oeste, no estado do Paraná. Sabe-se que a educação é influenciada por diversas mudanças que estão ocorrendo, exigindo do professor universitário o desenvolvimento ou aperfeiçoamento de novas técnicas e competências didático-pedagógicos. Nesse sentido, o objetivo principal deste estudo consiste em analisar as contribuições e limitações do Estágio Pedagógico Voluntário para a formação de professores no ensino superior dos egressos do curso de Bacharelado em Administração. O método de pesquisa utilizado foi estudo de caso único, pesquisa descritiva, com ênfase na pesquisa qualitativa; a coleta de dados foi realizada por meio de pesquisa documental e entrevista individual com ex-estagiários do programa EPV. Os resultados apontaram que o EPV contribui para o aprofundamento do conhecimento e aplicação dos conteúdos, possibilitando uma visão geral do aprendizado e da experiência como professor na sala de aula; no entanto, as limitações do EPV estão intimamente relacionadas com a própria falta de reflexões dessa prática educativa e a falta da concepção pedagógica do papel do educador. Conclui-se que o EPV, apesar de ser um programa que contribui para o desenvolvimento técnico dos egressos de Administração, apresenta ainda limitações voltadas para a formação didática e pedagógica.

Palavras-chave: Estágio pedagógico voluntário. Formação de professores. Práticas pedagógicas.

\section{Contributions and limitations of volunteer educational traineeship for the formation of management course teachers}

Abstract: This paper presents a reflection about teachers' formation in the Management Graduation Course, at the State University of Central West (Universidade Estadual do Centro-Oeste) in Parana State. It is known that education is influenced by a number of changes that are taking place, demanding from the university teacher, the development or improvement on new techniques, besides didactics and pedagogical skills. In this regard, the aim of the present study is to analyze the contributions and limitations of Volunteer Educational Traineeship (VET) for teacher formation in higher education in the management graduation course. The chosen research method was the single case study, a descriptive research, with its emphasis on qualitative research; the data collection was conducted through document search and individual interviews with former trainees from the VET program. Results showed that the program contributes to the deepening of knowledge and application of the contents, allowing an overview of the learning and of the teaching experience in the classroom; however, VET limitations are closely related to the lack of reflection on that educational practice and to the lack of the pedagogical conception about the educator role. It is concluded that the VET, in spite of being a program that contributed to the technical development of management graduates, it still has limitations focused on pedagogical and didactic formation.

Key words: Volunteer educational traineeship. Teacher formation. Pedagogical practices. 


\section{Introdução}

As mudanças proporcionadas na educação pelos agentes econômicos, sociais, culturais, tecnológicos e políticos exigem do docente de nível superior novas habilidades e competências didático-pedagógicos. Tardif (2012) defende que a formação dos professores envolve muitos saberes profissionais docentes para desempenhar efetivamente o seu trabalho diário, desenvolver as tarefas e atingir seus objetivos. Destaca-se o entendimento de Lourenço, Lima e Narciso (2016) que afirmam que a formação do professor universitário não envolve somente saberes do conteúdo de ensino, pois a prática pedagógica é complexa e contextualizada.

Nesse sentido, esta pesquisa procura investigar e debater quão importante é o Estágio Pedagógico Voluntário (EPV) no ensino superior para o desenvolvimento das habilidades e competências didático-pedagógicos para os egressos do curso de Administração que pretendem seguir carreira na docência universitária.

A pesquisa é relevante pois apresenta o EPV como um programa de suporte para a formação de professores do ensino superior, contribuindo para o desenvolvimento de habilidades e competências didático-pedagógicos para os egressos bacharéis que pretendem iniciar sua carreira como educadores. Macário, Elliot, Hildenbrand e Campos (2012) e Joaquim e Boas (2013) salientam a importância da universidade, bem como do estágio em docência, para o desenvolvimento das competências na formação dos professores, tendo em vista que a universidade é fonte do saber e ao mesmo tempo um ambiente real de prática para capacitação de novos docentes, uma vez que a formação de seus professores em nível de capacitação é decisivo para atender às demandas do contexto social atual.

Dessa forma, o objetivo principal deste estudo consiste em analisar as contribuições e limitações do Estágio Pedagógico Voluntário para a formação de professores no ensino superior no curso de Graduação em Administração. Diante dos desafios atuais impostos à educação, esta pesquisa visa responder à seguinte questão problemática: quais são as contribuições que o EPV fornece na formação, na profissionalização e no desenvolvimento das habilidades e competências docentes dos professores do curso de Graduação em Administração?

A estrutura deste artigo é composta pelo referencial teórico, que contextualiza as novas competências didático-pedagógicos, e apresenta o que as Leis de Diretrizes Nacionais da Educação (DCNs) indicam como competência para os acadêmicos do curso de Administração. Na sequência se descreve o método de pesquisa, e por fim, são apresentados, 
Contribuições e limitações do estágio pedagógico voluntário (EPV) para a formação de professores do curso de administração

analisados e discutidos os resultados quanto às contribuições e limitações do EPV, concluindo com as considerações finais do estudo e das referências que nortearam a pesquisa.

\section{Referencial Teórico}

\subsection{Contextualizações das Competências Didático-Pedagógicas}

As mudanças ocorridas nos últimos anos no âmbito econômico, político, social, ambiental e tecnológico influenciaram a educação das escolas e das universidades; dessa forma, o docente precisa ampliar sua formação para um caminho contínuo de aprendizado que se preocupe com as dimensões: humana, técnica, sociopolítica e educativa. Assim, o estudo das abordagens do processo ensino-aprendizagem evoluiu de ensino básico para uma nova fase caracterizada como didática fundamental, que se preocupa com a contextualização da prática pedagógica, a análise das diferentes metodologias de ensino e a reflexão sobre experiências teórico-práticas (ANDRÉ, 1992).

Para Orr e Simmons (2011), o papel social e educacional do docente é utilizar métodos e práticas pedagógicas modernas que objetivem o aprendizado e a criação do conhecimento dos jovens, de tal modo que os prepare para a vida. Lourenço, Lima e Narciso (2016, p. 1112) relatam que as diversas tarefas realizadas por um professor do ensino superior precisam abarcar [...] as dimensões epistemológicas - pedagógica e política da formação do docente universitário".

Korman (2015) contribui apontando algumas dimensões de métodos de ensinar e aprender que os professores podem utilizar para a aprendizagem dos alunos como: estimular a auto-observação, a problematização de fenômenos, o planejamento de como operacionalizar as tarefas, a flexibilidade de raciocínio, o pensamento lógico, a solução de problemas e a meta-cognição. Ao analisar a educação sob este aspecto, altamente social e humano, o mestre tem a seu cargo a mais séria função da vida em coletividade, não se limitando ao papel de simples repetidor de programas, mas sendo um animador de vocações que busca aplicações eficazes.

Masetto (2003) menciona que os professores devem se conscientizar de que o papel de docente no ensino superior é como o exercício de qualquer outra profissão, que exige capacitação própria e específica, não se restringindo, portanto, a apenas um diploma; exige-se competência pedagógica, pois o professor é um educador e constantemente deve refletir sobre suas questões prática-pedagógicas construídas a cada ano letivo e a cada turma. É preciso uma formação atrelada às competências das práticas pedagógicas para transpor a realidade atual, 
que é marcada por imprevistos e acontecimentos que requerem habilidades dos docentes, para os novos desafios postos à educação.

Desta maneira, Silva (2013, p. 7) orienta que os conteúdos estudados precisam operacionalizar os discentes com base "conceitual, procedimental e atitudinal para que possam saber sempre mais sobre o que estão aprendendo e tenham condições de representar o que foi estudado, o que foi aprendido e que tenham disposições para agir, sentir e posicionarse".

Há, nessa perspectiva, um extenso esforço no sentido de mediar o processo de construção do conhecimento pelos alunos, promovendo a aprendizagem e outras habilidades essenciais para o desenvolvimento de participantes ativos dentro da sociedade; assim, a prática de decorar conteúdos é substituída pela aquisição de grandes competências (FELIX; NAVARRO, 2009; SILVA, 2013).

Em uma visão construtivista, superar o conceito de ensino tradicional, é ir além de passar somente informações, é preciso desconstruir a relação passiva professor-aluno que se constitui somente no livro didático, num processo de transmissão de informações para o aluno, o qual repete e não interpreta a ligação com a realidade deixando de produzir sentido ao seu próprio aprendizado (FELIX; NAVARRO, 2009; SILVA, 2013).

Korman $(2015$, p. 31) avalia a pedagogia tradicional, tendo em vista que ela coloca o "professor no centro do ensino, com foco somente no aprimoramento do conhecimento técnico do docente, pensando que assim seu ensino irá melhorar, no entanto, isso só aumenta a diferença entre o que ele conhece e o que consegue ensinar".

Para Althaus (2004) e Orr e Simmons (2011) articular ensino, pesquisa e extensão é uma das maneiras de se debater a prática pedagógica nas universidades diante dos grandes desafios impostos à prática docente. Nessa lógica, combinar as duas ações didáticas de ensinar e aprender em uma classe nem sempre acontece, porque quem domina conhecimentos para atuação profissional muitas vezes não consegue dispor os mesmos para uma condição de aprendizagem. Na visão de Macário, Elliot, Hildenbrand e Campos (2012), a universidade é desafiada a satisfazer as exigências de uma comunidade numerosa e diversificada quanto aos seus interesses, necessidades, aptidões e habilidades.

Desse modo, Althaus $(2004$, p. 2) considera que um professor que "não compreender os conteúdos próprios de sua área de atuação, que serão objeto de sua ação didática", infelizmente não conseguirá planejar, conduzir e avaliar uma posição didática eficaz que conduzirá um crescimento da autonomia dos acadêmicos. Portanto, "se a docência é sua área de atuação, além das especificidades inerentes aos diferentes campos de conhecimento, a 
Contribuições e limitações do estágio pedagógico voluntário (EPV) para a formação de professores do curso de administração

didática também compõe o quadro de especificidades como conteúdo próprio da prática pedagógica universitária" (ALTHAUS, 2004, p. 2).

Tratando-se da formação de professores em instituições de ensino superior, Felden e Kronhardt (2011) afirmam que a universidade dedicada ao ensino superior independente do modelo estrutural e legal que adote, tem a obrigação, responsabilidade e seriedade com a nação local, regional e global para o desenvolvimento de habilidades e competências da preparação de formadores; assim, os professores estarão aptos para transformar o cotidiano dos alunos e eles escreveram uma nova estória e um novo porvir.

A formação de um corpo docente é contínua no sentido de criar, em uma atmosfera de constantes transformações e informações, a capacidade de construção do conhecimento. Gilleard (1998) avalia que, na essência da transmissão de conhecimentos para os seus alunos, professores necessitam de capacitação e/ou treinamento, visando que essa atividade se torne construtiva para seus alunos.

Dessa forma, além do educador planejar e organizar sua rotina de trabalho, ele precisa enfrentar os desafios de atender às novas habilidades e competências propostas por Perrenoud (2000) para satisfazer as circunstâncias educacionais contemporâneas.

Na sequência, o próximo tópico discorrerá sobre as novas competências didáticas do contexto atual.

\subsubsection{As Competências Educacionais Contemporâneas}

O conceito de competência pedagógica está relacionado com o papel de educador, cujo compromisso é contribuir eficientemente para que os estudantes aprendam; esse é seu propósito e responsabilidade. A fim de cumprir bem seu ofício precisa, necessariamente, de uma formação pedagógica (MASETTO, 2003). Faria (2010, p. 1) afirma que "competência pedagógica é buscar incessantemente o aprendizado, saberes necessários à prática educativa juntamente com valores éticos e morais, formando cidadãos capazes de produzir e construir sua própria identidade". Nesse âmbito, Machado, Sampaio, Macedo, Figueiredo, Rodrigues Neto, Lopes e Leite (2017) destacam que os professores precisam efetivar mudanças em suas práticas e aceitar que precisam ser educadores críticos e reflexivos, buscando, para isso, desenvolver certas competências.

A formação dos professores é composta de muitos saberes profissionais docentes necessários para desempenhar efetivamente o seu trabalho diário, desenvolver as tarefas e atingir seus objetivos. Os movimentos de profissionalização são a renovação dos princípios 
epistemológicos da missão de ser um professor, onde a mesma profissionalização e a formação para o ensino são o caminho para o qual convergem os dirigentes da educação; mudanças pedagógicas e outras ideologias de formação precisam agrupar-se para atender aos desafios inerentes à educação (TARDIF, 2012).

Joaquim, Nascimento, Boas e Silva (2011a); Araújo, M., de Melo, Silva, Lima, Araújo, J. (2014) destacam a contribuição do estágio docente para a adoção e implantação de novas metodologias de ensino, ressaltando-se a importância do professor orientador na condução das práticas pedagógicas. Joaquim e Boas (2013) apontam como ponto crucial a dificuldade enfrentada pelos professores iniciantes em ajustar teoria e prática em sala de aula. Em ambos os casos, os autores fazem menção ao papel relevante da presença assídua do professor experiente. Joaquim e Vilas Boas (2011b) e Joaquim, Vilas Boas e Carrieri (2012) destacam que o professor iniciante necessita obter feedback para que possa avaliar seus pontos fortes e fracos, no sentido de melhoramento contínuo e desenvolver maiores habilidades.

Perrenoud (2000) elucida nesse cenário, dez competências didático-pedagógicas para ensinar e ser professor nesse novo contexto, as quais são apresentadas no Quadro 1.

\section{Quadro 1 - As dez novas competências didático-pedagógicos para ensinar}

\begin{tabular}{|c|c|}
\hline Competências & Descrição das competências \\
\hline $\begin{array}{l}\text { Organizar e dirigir } \\
\text { situações de } \\
\text { aprendizagem }\end{array}$ & $\begin{array}{l}\text { Conhecer a disciplina, os conteúdos e objetivos de aprendizagem; trabalhar a } \\
\text { partir das representações dos alunos; trabalhar a partir dos erros e dos obstáculos } \\
\text { à aprendizagem; construir e planejar dispositivos e sequências didáticas; envolver } \\
\text { os alunos em projetos e atividades de pesquisa e de conhecimento. }\end{array}$ \\
\hline $\begin{array}{c}\text { Administrar a progressão } \\
\text { da aprendizagem }\end{array}$ & $\begin{array}{l}\text { Conceber e administrar situações-problemas ajustadas ao nível e as possibilidades } \\
\text { dos alunos; adquirir uma visão longitudinal dos objetivos de ensino; estabelecer } \\
\text { laços com as teorias subjacentes às atividades de aprendizagem; observar e } \\
\text { avaliar os alunos em situações de aprendizagem com uma abordagem formativa; } \\
\text { fazer balanços periódicos de competências, rumo a ciclos de aprendizagem. }\end{array}$ \\
\hline $\begin{array}{l}\text { Conceber e fazer evoluir } \\
\text { os dispositivos de } \\
\text { diferenciação }\end{array}$ & $\begin{array}{l}\text { Administrar a heterogeneidade no âmbito de uma turma; abrir e ampliar a gestão } \\
\text { de classe para espaço mais visto; fornecer apoio integrado; trabalhar com alunos } \\
\text { portadores de dificuldades de aprendizagem; desenvolver cooperação entre os } \\
\text { alunos e certas formas simples de ensino mútuo, uma dupla construção. }\end{array}$ \\
\hline $\begin{array}{l}\text { Envolver os alunos em } \\
\text { suas aprendizagens e em } \\
\text { seu trabalho }\end{array}$ & $\begin{array}{l}\text { Suscitar o desejo de aprender; explicitar a relação com o saber, o sentido do } \\
\text { trabalho escolar e desenvolver a capacidade de autoavaliação; instituir com o } \\
\text { conselho de alunos e negociar diversos tipos de regras e de contratos com eles; } \\
\text { oferecer atividades opcionais de formação; favorecer a definição de um projeto } \\
\text { pessoal de vida ao aluno. }\end{array}$ \\
\hline Trabalh & $\begin{array}{l}\text { Dirigir um grupo de trabalho; conduzir reuniões; formar e renovar uma equipe } \\
\text { pedagógica; enfrentar e analisar em conjunto situações complexas, práticas e } \\
\text { problemas profissionais; administrar crises ou conflitos interpessoais. }\end{array}$ \\
\hline $\begin{array}{c}\text { Participar da } \\
\text { administração da escola }\end{array}$ & $\begin{array}{l}\text { Elaborar, negociar um projeto da instituição; administrar os recursos da } \\
\text { universidade; coordenar, dirigir uma escola com todos os seus parceiros; } \\
\text { organizar e fazer evoluir, no âmbito da escola, a participação dos alunos, criando } \\
\text { competências para trabalhar em ciclos de aprendizagem. }\end{array}$ \\
\hline $\begin{array}{l}\text { Informar e envolver os } \\
\text { pais }\end{array}$ & $\begin{array}{l}\text { Dirigir reuniões de informação e de debate; envolver os pais na construção dos } \\
\text { saberes. }\end{array}$ \\
\hline
\end{tabular}


Contribuições e limitações do estágio pedagógico voluntário (EPV) para a formação de professores do curso de administração

\begin{tabular}{|c|l|}
\hline $\begin{array}{c}\text { Utilizar novas } \\
\text { tecnologias }\end{array}$ & $\begin{array}{l}\text { Utilizar editores de texto; explorar as potencialidades didáticas dos programas em } \\
\text { relação aos objetivos do ensino; comunicar-se à distância por meio da telemática; } \\
\text { utilizar as ferramentas multimídia de ensino, competências fundamentais em uma } \\
\text { cultura tecnológica. }\end{array}$ \\
\hline $\begin{array}{c}\text { Enfrentar os deveres e os } \\
\text { dilemas éticos da } \\
\text { profissão }\end{array}$ & $\begin{array}{l}\text { Prevenir a violência, na universidade e fora dela; lutar contra os preconceitos e as } \\
\text { discriminações sexuais, étnicas e sociais; participar da criação de regras de vida } \\
\text { comum referentes à disciplina na escola, às sanções e à apreciação da conduta; } \\
\text { analisar a relação pedagógica, a autoridade e a comunicação em aula; desenvolver } \\
\text { o senso de responsabilidade, a solidariedade e o sentimento de justiça, dilemas e } \\
\text { competências. }\end{array}$ \\
\hline $\begin{array}{c}\text { Administrar sua própria } \\
\text { formação contínua }\end{array}$ & $\begin{array}{l}\text { Saber explicitar as próprias práticas; estabelecer seu próprio balanço de } \\
\text { projeto de formação comum com os demais (equipe, universidade, rede); } \\
\text { envolver-se em tarefas em escala de uma ordem de ensino ou do sistema } \\
\text { educativo; acolher a formação dos colegas e participar dela; ser agente do sistema } \\
\text { de formação contínua. }\end{array}$ \\
\hline
\end{tabular}

Fonte: PERRENOUD, P. 10 novas competências para ensinar. Porto Alegre: Artes Médicas Sul, 2000.

O Quadro 1, apresenta dez competências que os docentes devem adquirir para que o ensino seja melhorado e aperfeiçoado, a fim de atingir seus objetivos; assim, além de passar conceitos, contextualizar, administrar situações de problema, colaborar para o processo de ensino e aprendizagem, desenvolver o espírito de trabalho em equipe, acompanhar as tendências dos alunos, usar ferramentas e as novas tecnologias, precisam saber administrar sua própria formação.

Machado, Sampaio, Macedo, Figueiredo, Rodrigues Neto, Lopes e Leite (2017) apontam a necessidade das universidades refletirem sobre as competências docentes; nesse aspecto, mencionam que a prática cotidiana proporciona ao professor desenvolver habilidades e competências para formação docente. Acrescentam ainda que é preciso que ocorram mudanças na gestão e que haja elaboração de programas que foquem o desenvolvimento de competências para os professores, com o propósito de melhorar o ofício da docência.

A formação continuada precisa abordar os problemas e os desafios das escolas e das universidades no contexto em que está inserida, observando o desenvolvimento do conhecimento, da ciência e da tecnologia que permitirá refletir criticamente para o aperfeiçoamento da prática pedagógica. Assim, as mudanças na educação devem convergir para um novo horizonte, onde os profissionais educadores vislumbrem o atendimento das novas competências didático-pedagógicos (DOURADO, 2015).

"A formação do professor universitário tem sido entendida, por força da tradição e ratificada pela legislação, como atinente aos saberes do conteúdo de ensino" (LOURENÇO; LIMA; NARCISO, 2016, p. 1). Nesse cenário, destacam que ser professor nos dias de hoje 
não é apenas saber dominar o conteúdo, e sim, uma "série" de questões complexas que fazem parte da prática pedagógica dos professores.

A fim de se verificar a formação pedagógica dos egressos do curso de Administração no EPV, serão expostas, no próximo tópico, as Diretrizes Nacionais de Educação do Curso de Graduação em Administração.

\subsubsection{Diretrizes Nacionais de Educação do Curso de Administração}

"As Diretrizes Curriculares Nacionais dos Cursos de Graduação em Administração pela Lei $\mathrm{n}^{\circ}$ 9.131, de 25 de novembro de 1995, pareceres CNE/CES de 776/97 e 583/2001 homologados pelo Ministro de Estado da Educação em 2/6/2003, 9/9/2003, 24/9/2004 e 3/6/2005" descrevem a formação básica de um aluno formado em Administração (MEC, 2005, p. 1).

Apresenta-se, no Art. $2^{\circ}$ da referida lei, "o perfil do formando, as competências e habilidades, a grade curricular, as atividades curriculares complementares, o sistema de avaliação, o projeto de iniciação científica, [...] e outros aspectos que tornem consistente o projeto pedagógico" (MEC, 2005, p. 1). No Quadro 2, são apresentados os objetivos e as competências de um profissional formado em Administração:

\section{Quadro 2 - Objetivos e Competências do Curso de Graduação em Administração (Bacharelado)}

\section{Objetivos e Competências}

I. Reconhecer e definir problemas; equacionar soluções; pensar estrategicamente; introduzir modificações no processo produtivo; atuar preventivamente; transferir e generalizar conhecimentos e exercer, em diferentes graus de complexidade, o processo da tomada de decisão.

II. Desenvolver expressão e comunicação compatíveis com o exercício profissional, inclusive nos processos de negociação e nas comunicações interpessoais ou intergrupais.

III. Refletir e atuar criticamente sobre a esfera da produção, compreendendo sua posição e função na estrutura produtiva sob seu controle e gerenciamento.

IV. Desenvolver raciocínio lógico, crítico e analítico para operar com valores e formulações matemáticas presentes nas relações formais e causais entre fenômenos produtivos, administrativos e de controle, expressando-se de modo crítico e criativo diante dos diferentes contextos organizacionais e sociais.

V. Ter iniciativa, criatividade, determinação, vontade política e administrativa, vontade de aprender, abertura às mudanças e consciência da qualidade e das implicações éticas do seu exercício profissional.

VI. Desenvolver capacidade de transferir conhecimentos da vida e da experiência cotidianas para o ambiente de trabalho e do seu campo de atuação profissional, em diferentes modelos organizacionais, revelando-se profissional adaptável.

VII. Desenvolver capacidade para elaborar, implementar e consolidar projetos em organizações.

VIII. Desenvolver capacidade para realizar consultoria em gestão e administração, pareceres e perícias administrativas, gerenciais, organizacionais, estratégicos e operacionais.

Fonte: BRASIL. Ministério da Educação. Secretaria de Educação Básica. Leis de Diretrizes Nacionais de Educação (LDB) do Curso de Administração. Brasília, DF, jul. 2005. Disponível em <http://portal.mec.gov.br/cne/arquivos/pdf/rces004_05.pdf>. Acesso em: jul. 2015. 
Contribuições e limitações do estágio pedagógico voluntário (EPV) para a formação de professores do curso de administração

De acordo com os objetivos e competências expostos acima, o curso de Graduação em Administração no Brasil não possui, segundo os propósitos de formação e competências acadêmicas dos formandos, formação específica voltada para a atuação de docentes. Na opinião de Lourenço, Lima e Narciso (2016), as leis de diretrizes nacionais de educação no Brasil que orientam a formação dos docentes são fracas e tímidas, uma vez que não contemplam políticas públicas que favoreçam os conhecimentos específicos da prática docente para a formação de um professor do ensino superior.

As novas Diretrizes Curriculares Nacionais (DCNs) ressaltam a profissionalização do ensino e a formação continuada dos professores, sendo aprovada no Congresso Nacional sob a Lei $\mathrm{n}^{\circ} 13.005 / 2014$. Essa nova fase para as políticas educacionais brasileiras busca maior organicidade na educação nacional nos próximos decênios, posto que o novo plano designou 20 metas e estratégias para a educação básica e superior, considerando em suas etapas discussões sobre a qualidade, avaliação, gestão educacional e reconhecimento dos professores (DOURADO, 2015).

Dourado (2015) direciona os formados não licenciados para uma formação didática, em caráter urgente e provisório, no sentido de compreender os aspectos coletivos, organizacionais e profissionais, além de repensar o método pedagógico dos saberes e valores nas atividades de extensão, nos grupos de estudos, nos encontros pedagógicos, nos cursos e programas para a formação exigida ao exercício da docência, tendo como principal objetivo a reflexão sobre a prática didática para o aperfeiçoamento técnico, ético, político e pedagógico do profissional docente.

Nesse aspecto, pondera-se haver maiores dificuldades para a formação docente para os professores do curso de Administração. Lourenço, Lima e Narciso (2016, p. 15) reforçam que faltam políticas que desenvolvam competências que auxiliem na compreensão do que é ser um professor universitário; percebem nesse quesito "um silêncio sobre a dimensão do ensino no fazer e ser docente". Portanto, para o curso de Administração, seria necessária uma qualificação para os professores, com uma disciplina específica de formação docente; entende-se que um professor em sala de aula sem esta formação é tornar o ensino e a aprendizagem precários para os estudantes.

Destarte, Dourado (2015) ainda afirma que a base para a formação inicial e continuada acontece por meio da articulação entre graduação e pós-graduação, pesquisa e extensão, como princípio essencial ao exercício da docência e do desenvolvimento do profissional educador. Dessa maneira, a docência é uma ação educativa intencional e metódica, que circunda conhecimentos específicos, pedagógicos e interdisciplinares fundamentados em metodologias 
como compromisso social, com a construção de conhecimento, com a gestão democrática e com a conversação permanente entre as várias visões de mundo.

As habilidades e competências necessárias à docência dizem respeito à formação de conhecimentos pedagógicos que compreendem articuladores teórico-prático, reflexão crítica, complementação da formação e experiências anteriores, participação na organização e gestão do sistema educacional e acompanhamento das dinâmicas pedagógicas e das experiências educativas ao longo do processo (DOURADO, 2015).

Para o entendimento da execução deste estudo, no tópico a seguir destaca-se o uso dos métodos utilizados para a construção da investigação que melhor responderam aos objetivos e ao problema de pesquisa.

\section{Procedimentos Metodológicos}

A pesquisa realizada concentra-se na pesquisa qualitativa. Este método foi escolhido por abordar melhor os projetos da Administração Pública, já que se presta a descrever as características de um determinado fato ou fenômeno, sendo realizado um aprofundamento dessa realidade referente a um tipo de serviço público destinado aos egressos de cursos de Administração em uma Universidade Pública do Estado do Paraná (ZANELLA, 2009).

Em um primeiro momento foram analisados os relatórios do Estágio Pedagógico Voluntário (EPV) de uma Universidade Estadual do Centro-Oeste do Paraná, buscando-se compreender os fenômenos do ponto de vista dos participantes do estágio pedagógico. Essa análise documental ocorreu por meio de uma verificação em 17 relatórios de estagiários do programa EPV do curso de Graduação em Administração, a coleta dessas informações foi realizada no período de janeiro a abril de 2016.

Dessa forma, foram analisados num quadro teórico, os objetivos e competências do programa EPV para a formação docente dos graduados, sendo relatados os dados indutivamente das experiências descritas nos relatórios dos alunos como contribuições e limitações do programa de estágio para o desenvolvimento da prática pedagógica do professor.

Na sequência, foram realizadas entrevistas individuais com ex-estagiários do programa EPV. Já as entrevistas foram feitas em Junho de 2016 com indivíduos que completaram os estágios nas disciplinas de gestão de pessoas e finanças. As entrevistas foram realizadas por meio de perguntas semiestruturadas; solicitou-se a permissão para o uso de gravador. Posteriormente à coleta, houve a transcrição das entrevistas e em seguida, a verificação pelo 
Contribuições e limitações do estágio pedagógico voluntário (EPV) para a formação de professores do curso de administração

método de análise de conteúdo de Bardin (2004), em que se evidencia a análise em categoria de palavras ou texto dos entrevistados procurando compreender as realidades por meio das mensagens.

\section{Análise dos Dados e Resultados}

Em atendimento às novas necessidades da formação docente para os egressos dos cursos de bacharelados como o de Administração encontra-se como apoio o projeto de extensão chamado "Programa de Estágio Pedagógico Voluntário da Universidade Estadual do Centro Oeste - Unicentro", regido sob a Resolução Nº01/2007-Cepe/Unicentro (UNICENTRO, 2007, p. 1).

Dentro das suas atribuições legais, o Programa de Estágio Pedagógico Voluntário prevê em seu “Art. $1^{\circ}$ o desenvolvimento de ações didático-pedagógicas, no âmbito das disciplinas regularmente ofertadas em cursos de graduação e sequenciais de formação específica da Universidade" (UNICENTRO, 2007, p. 5). Nesse âmbito, o Art. $3^{\circ}$ explana os objetivos desse programa e o Art. $6^{\circ}$ expõe as atividades dos participantes e de suas competências. O Quadro 3, apresenta os objetivos e competências do EPV:

\section{Quadro 3 - Objetivos, Competências e Atividades dos Participantes do Programa EPV}

\begin{tabular}{|l|}
\hline \multicolumn{1}{|c|}{ Objetivos do Programa Estágio Pedagógico Voluntário (EPV) } \\
\hline I - Implementar o processo de formação continuada dos graduados em nível superior. \\
\hline $\begin{array}{l}\text { II - Oportunizar o desenvolvimento da atividade de ensino das matérias do currículo pleno dos cursos de } \\
\text { graduação e sequenciais de formação específica da Universidade. }\end{array}$ \\
\hline $\begin{array}{l}\text { III - Cultivar interesse pelas atividades de estudo ligadas às linhas de pesquisa pertencentes aos grupos de } \\
\text { pesquisa dos Departamentos Pedagógicos. }\end{array}$ \\
\hline IV - Oportunizar ao estagiário ampliar seus conhecimentos com relação ao processo de ensino-aprendizagem. \\
\hline V - Auxiliar na formação de docentes para o ensino superior. \\
\hline \multicolumn{2}{|c|}{ Competências e Atividades dos Participantes do Programa EPV } \\
\hline $\begin{array}{l}\text { I - Participar das atividades didático-pedagógicas no âmbito da disciplina na qual executa o estágio } \\
\text { pedagógico voluntário. }\end{array}$ \\
\hline $\begin{array}{l}\text { II - Elaborar e executar, em conjunto com o Professor Orientador, o Plano de Atividades, obedecendo à } \\
\text { seriação da disciplina. }\end{array}$ \\
\hline III - Elaborar o Relatório Final de Atividades e entregar ao Professor Orientador. \\
\hline IV - Desenvolver demais atividades pertinentes. \\
\hline
\end{tabular}

Fonte: UNICENTRO. Universidade Estadual do Centro-Oeste do Paraná. Regulamento do Programa Estágio Pedagógico Voluntário. Paraná, 2007. Disponível em: <http://www2.unicentro.br/proen/files/2012/11/resolucao-01-2007.pdf>. Acesso em: fev. 2016.

Dessa forma, os objetivos e as competências desenvolvidos no programa EPV proporcionam ao aluno, o primeiro contato com a vida cotidiana de um educador; assim, o estagiário em parceria com o professor orientador, planeja, elabora e executa as atividades 
didáticas pedagógicas em sala de aula. Para corroborar com a discussão, os autores Felix e Navarro (2009) afirmam que somente a capacitação dos professores leva a uma boa execução do projeto que atenderá à exigência da didática dos dias atuais; somente uma formação adequada proporcionará uma atuação com desenvoltura e segurança em relação à nova proposta de ensino.

Assim sendo, para o trabalho de análise, foram selecionados 17 relatórios do Estágio Pedagógico Voluntário do curso de Graduação em Administração. Percebe-se, através destes documentos, que os egressos do curso de Administração vêm procurando desenvolver e intensificar as atividades de formação pedagógica para seguir em carreira na docência. Depois de efetuadas as análises dos relatórios, foram verificadas as contribuições do EPV no que tange ao desenvolvimento das habilidades e competências didáticas para a formação docente dos egressos do curso de Graduação de Administração. Nesse sentido, o Quadro 4, apresenta as habilidades e competências adquiridas pelos alunos estagiários do programa EPV do respectivo curso.

\section{Quadro 4 - Contribuições do Estágio Pedagógico Voluntário - EPV}

\begin{tabular}{|l|}
\multicolumn{1}{c|}{ Contribuições do EPV } \\
\hline Aprofundar e aplicar conhecimentos da área. \\
Compreender a dinâmica da área com as atividades de uma organização. \\
Assessorar o professor no desenvolvimento de suas atribuições como: planejamento de aulas, aplicações das \\
dinâmicas de grupo, elaboração e correção de trabalhos e avaliações. \\
Ajudar na exposição do conteúdo da disciplina, elaboração e execução de aulas em conjunto com o professor \\
e demais atividades do plano durante o ano letivo. \\
Elaborar práticas de técnicas de oratória e feedback. \\
Implementar o processo de formação continuada dos graduados em nível superior. \\
Oportunizar conhecimentos com relação ao processo de ensino-aprendizagem. \\
Proporcionar aprendizado/experiência na docência no ensino superior. \\
Acompanhar a didática na correção de trabalhos e provas. \\
Registrar e organizar o livro de classe. \\
Refletir a respeito da aptidão para atuar na profissão.
\end{tabular}

Fonte: Dados da pesquisa (2016).

As análises dos relatórios do EPV demonstraram que os egressos conseguem obter novas competências técnicas de conteúdo, ou seja, planejamento das atividades em sala de aula como: aplicações das dinâmicas de grupo, elaboração e correção de trabalhos e avaliações, a experiência da vivência cotidiana de um docente. Em apoio à esta análise, apresentam-se as entrevistas dos ex-estagiários que reforçam as contribuições e as experiências de quando realizaram o EPV: 
Contribuições e limitações do estágio pedagógico voluntário (EPV) para a formação de professores do curso de administração

A experiência para mim foi muito boa e positiva, porque sempre gostei de dar aula, sempre me senti bem apresentando trabalho, mas quando realmente você tem que ajudar a preparar uma aula, ajudar a ministrar uma aula, ter que preparar as questões de prova, você estar na prática é bem melhor (E1).

A experiência do Estágio Pedagógico Voluntário foi muito boa, porque contribui bastante para meu aprendizado, tanto para aprender novos conteúdos e como para saber como é o dia a dia de um professor, serve de base para evoluirmos naquilo que queremos ser (E2).

Quando os entrevistados foram questionados sobre qual atividade pedagógica achou mais interessante quando realizou o estágio, eles responderam: "Acho que a questão de ministrar as aulas foi o que eu achei mais interessante, preparar o conteúdo, estudar para ter que passar esse conteúdo para os alunos" (E1). "O que mais eu gostei foi as dinâmicas realizadas em sala de aula, porque se percebia o entusiasmo e a motivação dos alunos na realização dessa atividade" (E2). Nesse sentido, Dias e Lopes (2003) destacam o currículo para a formação de professores no Brasil levando em consideração o currículo por competências, a verificação do desempenho e a promoção dos professores por merecimento e eficiência.

Outras atividades realizadas pelos ex-estagiários foram citadas, como: "além de ministrar algumas aulas, ajudava nas chamadas e nas provas" (E1), "elaboração de atividades e exercícios, bastantes exercícios práticos depois da apresentação da teoria, eram utilizados muitos estudos de caso para exemplificação" (E2). Essas contribuições surgem no âmbito de aprofundamento dos conteúdos e temas da disciplina, no sentido de dar suporte para associar a teoria e as questões de atividades práticas nas organizações; essas contribuições gerais apresentam forte tendência basicamente voltada para o aporte das condições "físicas" para seguir na docência.

As habilidades e competências que mais foram desenvolvidas no EPV de acordo com ex-estagiários foram:

\footnotetext{
Acho que uma das maiores habilidades que aprendi dentro do estágio é de começar a aprender lidar com alunos, quando você é aluno, você olha para o professor, você imagina algo, gostaria que esse professor fosse assim e vice-versa, então essa habilidade de entender se o aluno está aprendendo ou se não está entendendo nada, essa habilidade da percepção das coisas foi minha maior habilidade (E1).

A maior habilidade que aprendi foi de como agir como professor, como se comunicar com os alunos, como preparar as aulas e provas, conhecimento mais aprofundado da disciplina e dos temas que iria lecionar (E2).
}

Nesse contexto, Masetto (2003) reforça que a primeira reflexão sobre as competências pedagógicas está direcionada para um planejamento como mecanismo de ação educativa, portanto, ao planejar sua disciplina o docente deve estar consciente de sua contribuição para a 
qualificação do aluno e do cidadão corresponsável pelas mudanças nas condições de vida da comunidade.

São diversas habilidades e competências pedagógicas requeridas que o educador necessita dominar para conseguir melhorar a educação. Segundo Perrenoud (2000), as novas competências enfatizam o saber do professor em organizar e coordenar situações de aprendizagem, em despertar os discentes para participação em projetos e atividades de pesquisa no âmbito da universidade, e em, a partir de uma visão mais ampla, avaliar o aluno por uma abordagem formativa, além de desenvolver a cooperação entre os alunos, favorecendo dessa maneira, a construção de um projeto pessoal de vida ao aluno.

Por conseguinte, percebeu-se nas declarações dos estagiários participantes do programa $\mathrm{EPV}$, que as habilidades e competências mais propiciadas foram às aplicabilidades e aprofundamentos de conteúdos específicos na área do conhecimento, isto é, as atividades docentes mais gerais e habituais do cotidiano do professor. Nessa perspectiva, o Quadro 5 evidencia algumas limitações do EPV para a formação de formadores diante da complexidade que é o ato de ensinar.

\section{Quadro 5 - Limitações do Estágio Pedagógico Voluntário - EPV}

\begin{tabular}{|c|} 
Limitações do EPV \\
\hline Falta proporcionar aprendizado das teorias pedagógicas na organização do processo de ensino. \\
Falta conhecimento da concepção pedagógica e das bases psicológicas de aprendizagem dos alunos. \\
Os alunos vão direto para a prática acompanhar o professor, e não para a reflexão do "porque" fazer \\
determinada atividade pedagógica. \\
Escassez do tempo do professor para passar orientações pedagógicas aos estagiários. \\
Falta de se analisar a influência das novas tecnologias no processo de ensino e aprendizagem. \\
Falta de reflexão sobre o Projeto político-pedagógico, plano de ensino do curso e da disciplina. \\
Falta de conhecimento das práticas didáticas pedagógicas. \\
Não apresenta inter-relação entre ensino, pesquisa e extensão. \\
na mudança de sua mentalidade, características e de suas habilidades. \\
Desafio no sentido de fazer com que o aluno compreenda o papel do profissional no seu processo de formação, \\
\hline
\end{tabular}

Fonte: Dados da pesquisa (2016).

Visando compreender o ponto de vista dos ex-estagiários sobre o que aprenderam sobre didática, um deles mencionou que "a didática na área de finanças é meio complicado, porque a gente pega muitos alunos que vem com dificuldades na matemática, [...] a questão da didática muitas vezes a gente tem que nivelar a turma para conseguir levar melhor a turma" (E1). Outro relatou: "aprendizagem sobre didática foi muito pouca coisa, quase nada foi ensinado sobre didática" (E2). Assim, a atividade docente no ensino superior não é somente uma atividade técnica, mas sim profundamente educativa; as repercussões de um 
Contribuições e limitações do estágio pedagógico voluntário (EPV) para a formação de professores do curso de administração

planejamento bem ou mal feito se estendem para além da sala de aula colaborando ou não para a educação dos jovens (MASETTO, 2003).

Portanto, se a "docência é sua área de atuação, além das especificidades inerentes aos diferentes campos de conhecimento, a didática também compõe o quadro de especificidades como conteúdo próprio da prática pedagógica universitária” (ALTHAUS, 2004, p. 2). Quando questionados sobre as dificuldades que sentiram ao realizar o EPV, os entrevistados responderam:

\begin{abstract}
Acho que a maior dificuldade que senti foi à questão da insegurança, ah...eu nunca dei aula, aí eu me senti inseguro em saber se o que eu estava fazendo era o certo, senti insegurança de algo que nunca tinha feito (E1).

Senti dificuldade em encontrar materiais antigos e materiais atualizados sobre o tema, bem como, não entender como o professor queria que as aulas fossem realizadas, receio em saber se era isso mesmo que queria que fosse passado (E2).
\end{abstract}

Althaus (2004) menciona os grandes desafios que são impostos à prática docente no ensino superior, no sentido de vincular as atividades didáticas de ensino e aprendizagem no ambiente da sala de aula, porque nem sempre quem detém os conhecimentos da atuação profissional consegue os transpor para uma condição de aprendizagem.

O docente precisa utilizar mecanismos que aconselhe os universitários a serem capazes de possuir autonomia, tomar atitudes e expandir projetos de cidadania. Nessa perspectiva, e para que isso aconteça, o professor precisa conhecer e ter consciência das teorias de concepção pedagógicas para conseguir embasar sua prática e ajudar os discentes a encontrar melhores caminhos para a aprendizagem (GIESTA, 2002).

Quando perguntado aos ex-estagiários sobre a reflexão das atividades realizadas, se eles entendiam o "porquê" da elaboração de determinada atividade, as respostas foram as seguintes:

Sempre... sempre todas as atividades realizadas ficavam claro o porquê dessa atividade ser passada
aos alunos, sempre tinha conversa antes sobre a importância daquela atividade (E1).

A reflexão sobre o porquê de passar as atividades, no sentido de saber qual era o propósito dessa atividade foi realizada até certo momento do estágio, depois não foi mais realizado (E2).

No entanto, a análise dos relatórios apontou que a maior parte dos alunos do EPV realizaram as atividades propostas pelos professores, mas não tiveram consciência e reflexão do "porquê" efetuam aquela determinada atividade, qual o propósito dela para a aprendizagem da turma, ou seja, qual o objetivo fim dessa proposta de atividade, o que os acadêmicos precisam aprender com esse trabalho. 
Assim, os docentes necessitam dessas habilidades e competências didáticas pedagógicas para engajar uma educação integrada, participativa e permanente. [...] "refletir sobre seu papel de formador de formadores é essencial, olhar para o aluno como alguém que precisa de constante orientação e estímulo para aprender, assim tornar um cidadão digno de formação" (FREIRE, 2014, p. 46). Mello (2007) relata que a análise da atuação pedagógica demonstrou que a mudança significativa na educação brasileira acontecerá quando o professor compreender a profunda razão de ser da sua prática docente, e da sua opção política no seu agir pedagógico. Na visão dos ex-estagiários, o EPV pode apresentar algumas desvantagens como:

Não ser remunerado e outra desvantagem talvez sejam os estagiários serem muito inexperiente (E1).

Quando o professor não auxilia o estagiário pode acontecer à desmotivação, e o estagiário ficar sem um norte do que fazer sobre as atividades do estágio (E2).

Desse modo, o aporte que o EPV fornece aos egressos do curso de Graduação em Administração é limitado quanto à capacidade de desenvolver as habilidades didáticas abordadas pelas dez novas competências. Nessa perspectiva, os egressos do curso vislumbram uma oportunidade de entrar em contato com essa realidade pedagógica, por meio do Estágio Pedagógico Voluntário (EPV), sendo esta a grande contribuição do EPV para a formação inicial do profissional docente.

Dessa forma, o programa acaba por ser um "estopim" inicial para a formação de professores no ensino superior, portanto, para a profissionalização do egresso no sentido de atender às dez novas competências didático-pedagógicos exigidas no contexto atual. $\mathrm{O}$ egresso precisa buscar em paralelo ao estágio uma formação específica, seja em cursos de especialização, mestrado e/ou doutorado ou ainda na integração do ensino, da pesquisa e da extensão. Estes programas têm o sentido de "olhar" para as novas competências didáticopedagógicos para ensinar na contemporaneidade, atendendo aos desafios impostos no âmbito psicológico, social, econômico, político e acadêmico.

Freire (2014, p. 86) aponta [...] "a importância e a urgência da democratização das escolas e universidades públicas, da formação permanente de seus educadores e educandos para a transformação do indivíduo e da sociedade". Assim sendo, os egressos dos cursos de bacharelados têm uma lacuna a ser preenchida, porque ao fazer o estágio pedagógico voluntário, o egresso não possui habilidades e competências das ações didáticas pedagógicas, pois sua formação não possibilita conhecimento da área de ensino superior, mas somente conhecimento e atividades voltadas para atuação como administrador; vários egressos 
Contribuições e limitações do estágio pedagógico voluntário (EPV) para a formação de professores do curso de administração

seguem, no entanto, a carreira de docente, sem o conhecimento da concepção pedagógica e dos fundamentos epistemológicos.

Assim, para melhorar a qualidade da capacitação docente são essenciais conhecimentos sobre as ações didático-pedagógicas, a estrutura psicológica de aprendizagem dos alunos, o entendimento do dilema ético da profissão, o combate aos preconceitos e as discriminações sociais, sexuais e étnicas, a apreciação da conduta e a análise da relação pedagógica, a fim de criar o senso de responsabilidade sobre suas próprias práticas e sobre o desenvolvimento de suas competências (PERRENOUD, 2000).

O EPV é, portanto, o primeiro estágio da formação continuada dos egressos, não sendo suficiente do ponto de vista da análise dos objetivos e atividades, bem como, do ponto de vista dos entrevistados para atender à formação docente.

Nesse caminho, podem-se sintetizar contribuições que Carvalho e Gil-Pérez (1993) explanam sobre o modelo construtivista: é mais importante conceber o currículo como um programa de atividades que possibilita os conhecimentos e habilidades que precisam ser adquiridos e construídos.

\section{Considerações Finais}

Com as exigências dos agentes econômicos, sociais, culturais, tecnológicos e políticos, o ensinar e aprender educacional exigem do docente de nível superior novas habilidades e competências didáticas pedagógicas. Tardif (2012) entende que a formação dos professores envolve muitos saberes profissionais em relação à docência para desempenhar seu papel de educador. Nesse sentido, Perrenoud (2000) enfatiza as dez novas habilidades e competências didático-pedagógicos para ensinar nesse contexto moderno.

Dessa maneira, as mudanças recentes nas Diretrizes Básicas de Educação Nacional apontam para a necessidade de os cursos de Bacharelados direcionarem atividades para formação e profissionalização dos egressos que pretendam seguir carreira na docência. Reforçam que o desenvolvimento das competências pedagógicas acontece por meio da oferta de uma disciplina isolada ou um curso pedagógico específico para os bacharéis; obtendo assim, uma formação continuada a fim de adquirir habilidades e competências pedagógicas que respondam aos problemas educacionais.

Nesse âmbito, o objetivo principal deste estudo consistiu em analisar as contribuições e limitações do Estágio Pedagógico Voluntário para a formação de professores no ensino superior dos egressos do curso de Graduação em Administração. Verificou-se, através da 
investigação, que as contribuições mais relatadas pelos estagiários foram no sentido de obter conhecimento técnico sobre os conceitos e as práticas, auxílio no que tange ao desenvolvimento de atividades burocráticas do ensino educacional. Já as maiores limitações apresentadas e percebidas diante da análise dos relatórios se referem à falta de consciência das compreensões do "porquê" desenvolver determinada atividade, e da importância da concepção pedagógica de um professor.

Consequentemente, ficam como sugestões de estudos futuros assuntos que abordem sobre concepção pedagógica e reflexão sobre o cotidiano prático educacional dos professores, devido à abrangência nos últimos tempos desses temas, a fim de que a profissão de professor seja um constante "olhar" crítico para a sua ideologia e prática pedagógica. As limitações desse estudo estão relacionadas à dificuldade do acesso aos relatórios para analisar as experiências dos estagiários como futuros professores.

Em linhas gerais, o EPV fornece uma base inicial para a contínua caminhada de um egresso bacharel para a docência; dessa forma, o objetivo do estudo foi alcançado evidenciando o aporte à formação e à profissionalização do desenvolvimento das habilidades didáticas pedagógicas dos egressos do curso de Administração.

Por fim, não há transformação da realidade da sociedade se o sistema educacional como um todo não funcionar, por isso, a necessidade de ir além do ato de ensinar e aprender dos alunos; as mudanças só acontecem com indivíduos críticos reflexivos sobre suas próprias atitudes.

\section{Referências}

ALTHAUS, M. T. M. Ação didática no ensino superior: à docência em discussão. Teoria e Prática da Educação, Maringá, v. 7, n. 1, p. 101-106, jan./abr. 2004. Disponível em: <http://www.maiza.com.br/adm/producao/5.pdf〉. Acesso em: 10 jul. 2014.

ANDRÉ, M. E. D. A. de. A evolução do ensino da didática. Revista da Faculdade de Educação, São Paulo, v. 18, n. 2, p. 241-246, jul./dez. 1992.

BARDIN, Laurence. Análise de conteúdo. 3. ed. Lisboa: Edições 70, 2004

CARVALHO, Anna Maria Pessoa de; GIL-PÉREZ, Daniel. Formação de professores de ciências: tendências e inovações. São Paulo: Cortez, 1993.

ARAÚJO, M. V. M.; DE MELO, F. A.; SILVA, L. V. L. da C.; LIMA, J. M. C.; ARAÚJO, J. K. B. Estágio docência: concepções epistemológicas e suas influências nas metodologias de ensino. Revista Administração, Rio de janeiro, v. 15, n. 2, p. 237-269, maio/jun. 2014.

BRASIL. Ministério da Educação. Secretaria de Educação Básica. Leis de Diretrizes Nacionais de Educação (LDB) do Curso de Administração. Brasília, DF, jul. 2005. Disponível em <http://portal.mec.gov.br/cne/arquivos/pdf/rces004_05.pdf〉. Acesso em: jul. 2015. 
Contribuições e limitações do estágio pedagógico voluntário (EPV) para a formação de professores do curso de administração

DIAS, R. E.; LOPES, A. C. Competências na formação de professores no Brasil: o que (não) há de novo. Revista Educação \& Sociedade, Campinas, v. 24, n. 85, p. 1155-1177, dez. 2003.

DOURADO, L. F. Diretrizes curriculares nacionais para a formação inicial e continuada dos profissionais do magistério da educação básica: concepções e desafios. Revista Educação \& Sociedade, Campinas, v. 36, n. 131, p. 299-324, abr./jun. 2015.

FARIA, M. A. T. Competência pedagógica do professor universitário. Revista Científica Online, Paracatu, v. 4, n. 12, 2010.

FELDEN, E. L.; KRONHARDT, C. A. C. A universidade e a formação de professores. Vivências Revista Eletrônica de Extensão da URI, Rio Grande do Sul, v. 7, n. 12, p. 37-45, maio 2011.

FELIX, F. A.; NAVARRO, E. C. Habilidades e competências: novos saberes educacionais e a postura do professor. Revista Eletrônica Interdisciplinar, Mato Grosso, v. 2, n. 2, set. 2009.

FREIRE, P. Pedagogia da esperança: um reencontro com a pedagogia do oprimido. São Paulo: Paz e Terra, 2014.

GIESTA, N. C. Histórias em quadrinhos: recursos da educação ambiental. Educação Ambiental: abordagens múltiplas. Porto Alegre: Artmed, 2002.

GILLEARD, J. Trainers need training too. Empowerment in Organizations, v. 6, n. 1, p. 19-26, 1998.

JOAQUIM, N. de F.; BOAS, A. A. V. Desafios da formação docente: estágio docência e a prática de ensino em Administração. Administração: Ensino e Pesquisa, Rio de Janeiro, v. 14, n.3, p. 617-652, 2013.

JOAQUIM, N. de F.; NASCIMENTO, J. P. de; BOAS, A. A. V.; SILVA, F. T. Estágio docência: um estudo no programa de Pós-Graduação em Administração da Universidade Federal de Lavras. RAC-Revista de Administração Contemporânea, v. 15, n. 6, p. 11371151, 2011a.

JOAQUIM, N. de F.; VILAS BOAS, A. A.; CARRIERI, A.P. Entre o discurso praticado e a realidade percebida no processo de formação docente. Avaliação. Campinas; Sorocaba, v. 17, n. 2, 2012.

JOAQUIM, N de F.; VILAS BOAS, A. A. Tréplica-Formação Docente ou Científica: o Que Está em Destaque nos Programas de Pós-Graduação? RAC-Revista de Administração Contemporânea, Curitiba, v. 15, n. 6, 2011 b.

KORMAN, R. F. Os efeitos da reforma curricular na sala de aula em um curso de engenharia. 191f. 2015. Dissertação (Mestrado em Engenharia de Produção) - Universidade Federal do Rio Grande do Sul, Porto Alegre, 2015.

LOURENÇO, C. D. da S.; LIMA, M. C.; NARCISO, E. R. P. Formação pedagógica no ensino superior: o que diz a legislação e a literatura em Educação e Administração? Avaliação, Campinas; Sorocaba, v. 21, n. 3, p. 691-718, nov. 2016. Disponível em: <http://www.scielo.br/pdf/aval/v21n3/1982-5765-aval-21-03-00691.pdf >. Acesso em: 02 out. 2016.

MACÁRIO, N. M.; ELLIOT, L. G.; HILDENBRAND, L.; CAMPOS, A. M. da S. FORMAÇÃO DE PROFESSORES: O estudo de competências e habilidades como pressuposto para a melhoria da formação profissional de educadores. In: REUNIÃO DE 
AVALIAÇÃO: Temas da Atualidade: Contribuições e Desafios da Avaliação, 2., 2012, Rio de Janeiro. Anais... Rio de Janeiro: Fundação Cesgranrio, 2012. p. 135.

MACHADO, M. M. B. C.; SAMPAIO, C. A.; MACEDO, S. M.; FIGUEIREDO, M. F. S.; RODRIGUES NETO, J. F.; LOPES, I. G.; LEITE, M. T. S. Reflexões e significados sobre competências docentes no ensino médico. Avaliação, Campinas; Sorocaba, v. 22, n. 1, p. 85104, mar. 2017. Disponível em: < http://www.scielo.br/pdf/aval/v22n1/1982-5765-aval-2201-00085.pdf >. Acesso em: 12 set. 2017.

MASETTO, M. T. Competência pedagógica do professor universitário. São Paulo: Summus, 2003.

MELLO, R. M. Metodologia de ensino. Telêmaco Borba - Paraná, 2007. Disponível em <http://estagiocewk.pbwiki.com/OTP>. Acesso em: 20 jan. 2016.

ORR, K.; SIMMONS, R. R. Restrictive practice: The work-based learning experience of trainee teachers in English further education colleges. Journal of Workplace Learning, v. 23, n. 4, p. 243-257, 2011.

PERRENOUD, P. 10 novas competências para ensinar. Porto Alegre: Artes Médicas Sul, 2000.

SILVA, L. R. Docência na contemporaneidade: desafios para professores no ensino superior. Revista Primus Vitam, São Paulo, v. 5, n. 4, jul. 2013.

TARDIF, M. Saberes docentes e formação profissional. 13.ed. Petrópolis, RJ: Vozes, 2012.

UNICENTRO. Universidade Estadual do Centro-Oeste do Paraná. Regulamento do

Programa Estágio Pedagógico Voluntário. Paraná, 2007. Disponível em

<http://www2.unicentro.br/proen/files/2012/11/resolucao-01-2007.pdf >. Acesso em: fev. 2016.

ZANELLA, L. C. H. Metodologia de estudo e de pesquisa em administração.

Florianópolis: UFSC - Departamento de Ciências da Administração, 2009.

Márcia Sierdovski

${ }^{1}$ Universidade Estadual do Centro-Oeste | Programa de Pós-Graduação em Administração| Guarapuava |PR | Brasil. Contato: marcia.sier@ hotmail.com

ORCID (D) http://orcid.org/ 0000-0002-7078-9831

Sílvio Roberto Stefano

${ }^{2}$ Universidade Estadual do Centro-Oeste | Programa de Pós-Graduação em Administração | Guarapuava | PR | Brasil. Contato: professor-silvio@ hotmail.com

ORCID iD http://orcid.org/0000-0002-5871-8686

Marcia Aparecida Zampier

${ }^{3}$ Universidade Estadual do Centro-Oeste | Programa de Pós-Graduação em Administração Guarapuava |PR | Brasil. Contato: marciazampier@gmail.com

ORCID (D) http://orcid.org/0000-0002-0298-6454

Elaine Aparecida Regiani de Campos

${ }^{4}$ Universidade Federal do Rio Grande do Sul | Programa de Pós-Graduação em Engenharia de Produção| Porto Alegre | RS | Brasil. Contato: earcamp@ gmail.com

ORCID iD http://orcid.org/0000-0002-9606-2593

Artigo recebido em 9 de julho de 2017 e aprovado em 20 de fevereiro de 2018. 